\author{
Military Technical College \\ Kobry El-Kobba \\ Cairo, Egypt
}

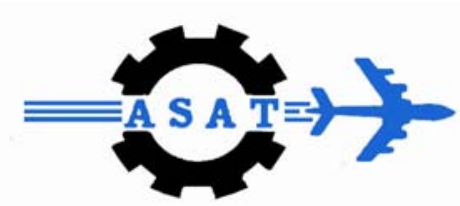

12-th International Conference

on Aerospace Sciences \& Aviation Technology

\title{
FEATURE INFLUENCE ON TARGET CLASSIFICATION PERFORMANCE USING THE HIGH RANGE RESOLUTION PROFILES
}

Brahim ATROUZ*, Hayet AIT OUAZZOU*, Hocine KIMOUCHE*

\begin{abstract}
We propose a supervised classification of aircrafts using the high range resolution profiles extracted from inverse synthetic aperture radar images. The principal components are extracted from pre-processed synthetic radar data before applying the 1-nearest neighbour classification. The classification performances are presented in terms of the correct classification probability. A classification performances comparison is presented for two types of data: The HRR profiles and the principal components of HRR profiles.
\end{abstract}

KEY WORDS: HRR profile, NCTR, ISAR, 1-Nearest Neighbour, PCA, classification.

\footnotetext{
* Microwave and Radar Laboratory, EMP, BP 17, Bordj El Bahri, Algiers
} Email: b-atrouz@caramail.com or hayetaitouazzou@hotmail.com Tel: 0021320314389 Fax: 0021321863204 


\section{INTRODUCTION}

It has been demonstrated that the High Range Resolution (HRR) profiles are discriminative for the Non Cooperative Target Recognition (NCTR) [1] [2] [3] [4]. In this work, we present a classification approach for 18 military non cooperative aircrafts using HRR profiles. The HRR radar data set used to this effect is extracted from considered ISAR target images that have been pre-processed using a binary transformation and a contour detection algorithm [5].

\section{HIGH-RANGE RESOLUTION PROFILES}

In this paper, we use HRR radar signals for non cooperative target classification. The HRR radar provides a 1-D picture of what the sensor is looking at. HRR signals are particularly hard to use for target recognition, partly because the 3-D world is projected onto just one dimension [1] [2] [6] (Fig. 1). A further complication to target identification using HRR is that signals change considerably with only small changes in azimuth and elevation [1] [2] [3] [4] [6].

\section{DATA}

The data set used in this work is synthetic. For each target (ISAR image), there are 96 range profiles consisting of 64 range bins. Each profile vector corresponds to an unknown target/radar orientation. Figure 2 shows some HRR profiles obtained for "A4" and "Mig27" targets.

\section{RADAR DATA PRE-PROCESSING}

The radar data are submitted to the following treatments:

- Hamming windowing [7];

- Box-Cox non linear compression [8] [9] [10];

- Normalisation.

Figure 3 shows the pre-processing effect applied to the HRR profiles.

The pre-processing operations applied to HRR vectors (obtained from ISAR images) improve considerably the Correct Classification Probability (CCP). (See Figure 4)

\section{FEATURE VECTORS}

We chose the Principal Component Analysis (PCA) as feature vectors in order to reduce the dimension of the vectors to 26 elements instead of 64 , preserving $99 \%$ of useful information on the data. Figure 5 shows some results of the principal component extraction. 


\section{ONE (1) NEAREST NEIGHBOUR CLASSIFICATION}

The classifier used for classification is based on the one-nearest-neighbour method $(1 \mathrm{NN})$. The metric distances are calculated between the training data set and the test data set [10]. The class is allotted to that whose metric distance is minimal. Two types of data are introduced to the 1-nearest-neighbour classifier: The processed HRR profiles and the principal components. For each type of data, the vector under test (the target's class is known) is compared to vectors of the training data.

Thus, we compare the obtained performances of classification for the two types of data. The diagram of Figure 6 summarizes the suggested approaches of the supervised classification.

\section{SIMULATION RESULTS}

We present some simulation results for 18 targets $(\mathrm{C} 1 \ldots, \mathrm{C} 18)$ in the form of confusion matrix knowing that $25 \%$ of the dataset represent the data of test. The remaining data constitute the training set. The obtained results are given in Fig. 7 and Fig. 8, for the unprocessed HRR profiles and principal components, respectively. We note that the CCP (the average of the diagonal elements of the confusion matrix) is slightly lower in the case of the principal components.

Fig. 9 and Fig. 10 show the comparison of the classification performances in terms of CPP, by considering the signal-to-noise ratio (SNR) and the number of the vectors in the training dataset, respectively.

We note that for a given value of SNR, the CPP is higher in the case of HRR profiles. The difference between the two curves is reduced as the SNR increases. We also note that the classification performance is as much better as the quantity of information in the training dataset is significant.

\section{CONCLUSION}

In this paper, we presented an aircraft classification approach using high range resolution profiles, extracted from ISAR images. The proposed approach uses the one (1) nearest neighbour classifier. A classification performances comparison was presented for two types of data: The HRR profiles and the principal components of HRR profiles.

The obtained results show that the classification performances using the processed HRR profiles are better than those obtained with the principal components.

This shows that the high resolution radar signature is rich in information and that the principal components are less selective for the synthetic high range resolution profiles used in this work.

To improve the classification performances, it would be interesting to use other types of features. 


\section{REFERENCES}

[1] H. Ait Ouazzou et B. Atrouz, "Classification of the targets radar by means of the High Radar Resolution profiles (HRR)", Magister thesis, EMP, Bordj El Bahri, Alger, 2005.

[2] R. Van Der Heiden, "Aircraft Recognition with Radar Range Profiles", PhD thesis, University of Amsterdam, 1998.

[3] Joris Portegies Zwart, "Aircraft Recognition from Features Extracted from Measured and Simulated Radar Range Profiles", PhD thesis, University of Amsterdam, October 2003.

[4] Steven P. Jacobs, Joseph A. O'sillivan, "Automatic Target Recognition Using Sequences of High Resolution Radar Range-Profiles", IEEE Transactions on Aerospace and Electronic Systems, Vol. 36, No. 2, April, 2000.

[5] Xuejun Liao, Paul Runkle and Lawrence Carin, "Identification of Ground Targets from Sequential High-Range-Resolution Radar Signatures". Technical Report for AFRL and MRC, Department of Electrical and Computer Engineering, Duke University, Durham, 2000.

[6] Donald R. Wehner. "High Resolution Radar", Artech house, Boston, London, second edition, 1994.

[[7] G.E.P. Box and D.R. Cox. "An Analysis of transformation". Journal of the Royal Statistical Society, Series B, 26:211-252, 1964.

[8] R.M. Sakia. "The Box Cox Transformation Technique". A review. The Statistician, 41:169-178, 1992.

[9] R. Van Der Heiden and F.C.A. Groen. "The Box-Cox Metric for Nearest Neighbour Classification Improvement”. Pattern Recognition, 30(2), 1997. 
Fig. 1 : Return radar signal projection onto the line of sight of the radar.

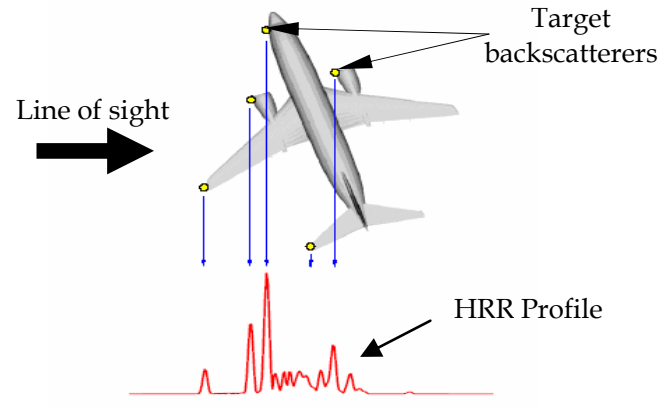

Fig. 2 : ISAR / HRR Extraction. Targets "A4 and Mig27".

(a)

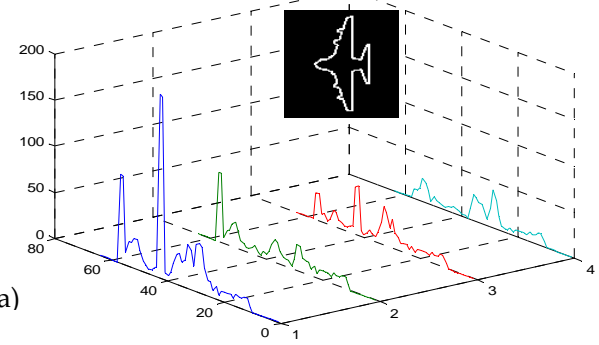

(b)

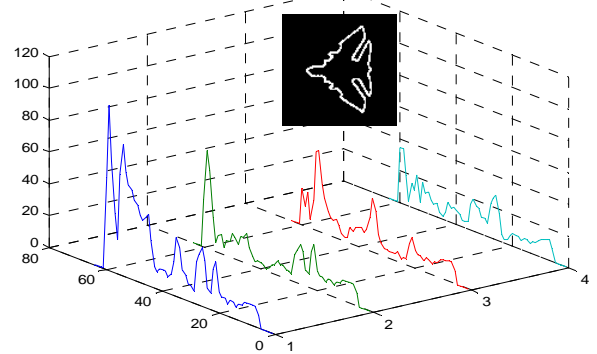

Fig. 3 : Pre-processing effect applied to the HRR profiles "Target F111" (a) Unprocessed HRR Profiles (b) Hamming windowing (c) Box - Cox $\begin{array}{ll}\text { Compression } & \text { (d) Windowing + Compression + Normalization }\end{array}$

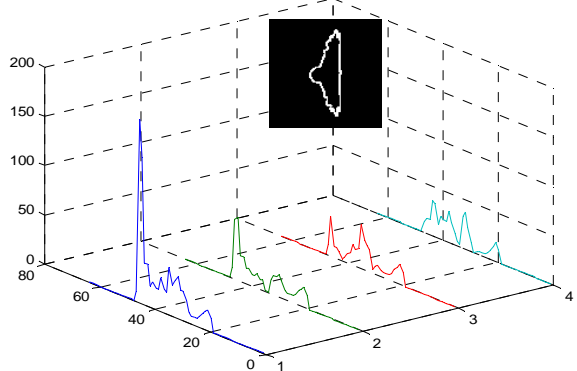

$(\mathrm{a}$

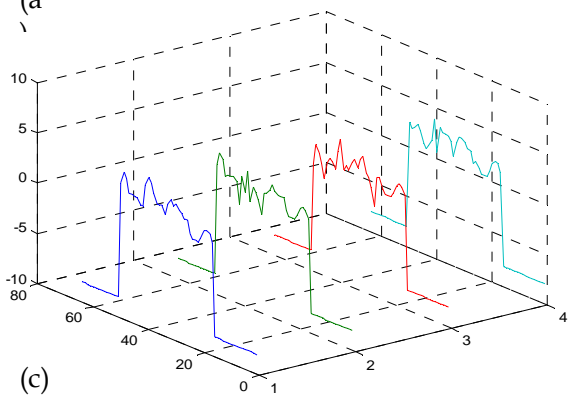

(b)

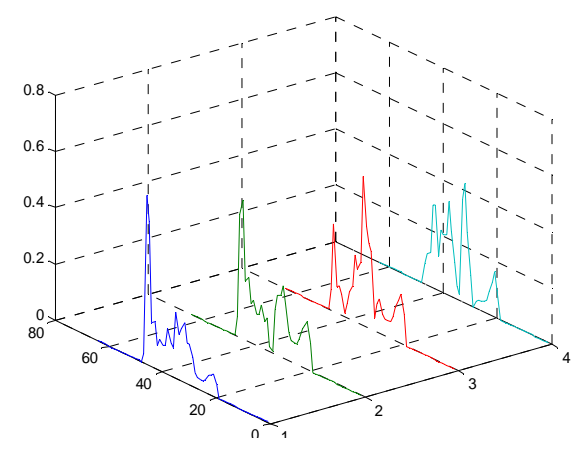

$(\mathrm{d}$

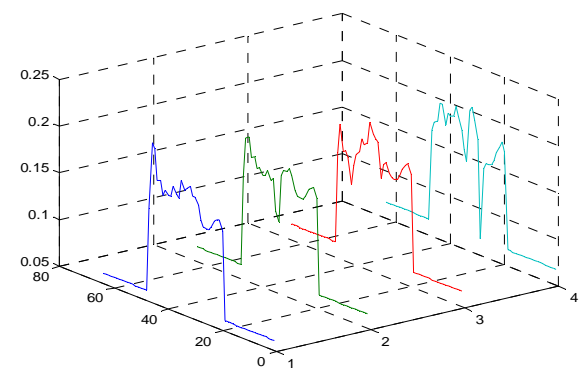


Fig. 4 : Performance improvement preprocessing effect on the correct classification probability - Pcc.

\begin{tabular}{||c||c||c||}
\cline { 3 - 3 } \multicolumn{1}{c||}{} & $\begin{array}{c}\text { Unprocessed } \\
\text { data }\end{array}$ & $\begin{array}{c}\text { Processed } \\
\text { data }\end{array}$ \\
\hline \hline HRR & 0.9484 & 0.9977 \\
\hline \hline PCA & 0.9511 & 0.9800 \\
\hline
\end{tabular}

Fig. 5: The principal components extracted from the HRR data, " Targets : Jaguar and Mirage".

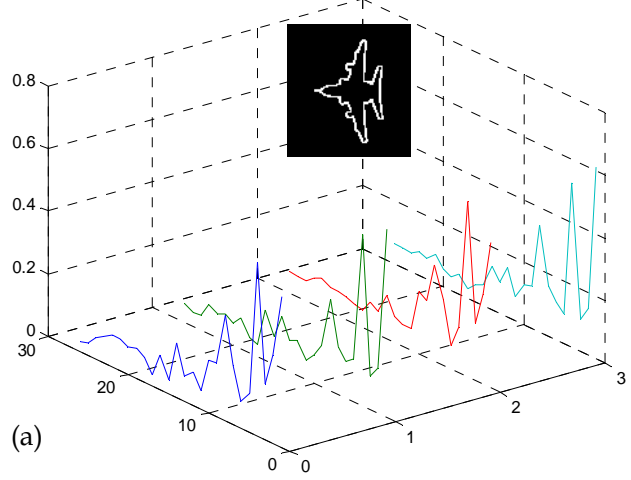

(b)

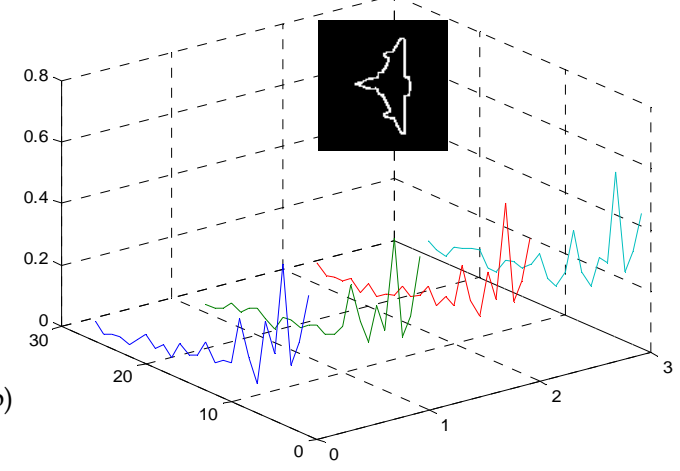

Fig. 6 : The proposed classification approaches.
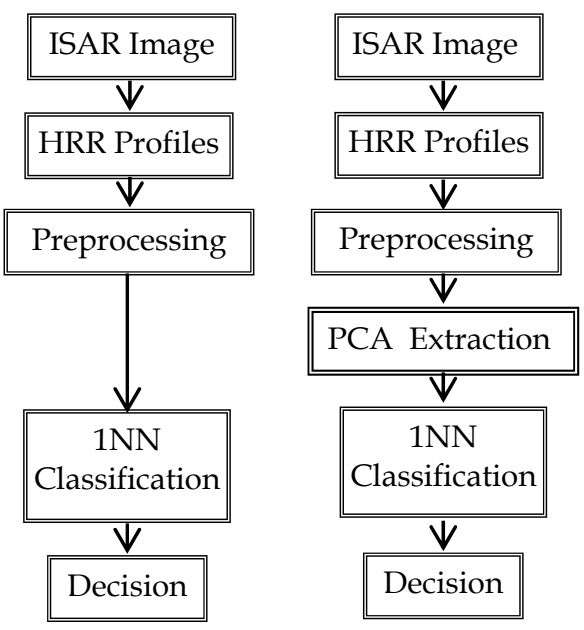
Fig. 7 : Confusion matrix for the 18 targets - HRR profiles -

\begin{tabular}{|c|c|c|c|c|c|c|c|c|c|c|c|c|c|c|c|c|c|}
\hline & 12 & 23 & 4 & & & & 8 & & & & & 13 & 14 & 15 & & & \\
\hline 1 & 10 & $\begin{array}{lll}0 & 0\end{array}$ & 0 & 0 & 0 & 0 & 0 & 0 & 0 & 0 & 0 & 0 & 0 & 0 & 0 & 0 & 0 \\
\hline 2 & $\begin{array}{ll}0 & 1\end{array}$ & 10 & 0 & 0 & 0 & 0 & 0 & 0 & 0 & 0 & 0 & 0 & 0 & 0 & 0 & 0 & 0 \\
\hline 3 & $\begin{array}{ll}0 & 0\end{array}$ & $\begin{array}{ll}0 & 1\end{array}$ & 0 & 0 & 0 & 0 & 0 & 0 & 0 & 0 & 0 & 0 & 0 & 0 & 0 & 0 & 0 \\
\hline 4 & 0 & $\begin{array}{ll}0 & 0\end{array}$ & 1 & 0 & 0 & 0 & 0 & 0 & 0 & 0 & 0 & 0 & 0 & 0 & 0 & 0 & 0 \\
\hline 5 & $\begin{array}{ll}0 & 0\end{array}$ & 0 & 0 & 1 & 0 & 0 & 0 & 0 & 0 & 0 & 0 & 0 & 0 & 0 & 0 & 0 & 0 \\
\hline 6 & 0 & $\begin{array}{ll}0 & 0\end{array}$ & 0 & 0 & 1 & 0 & 0 & 0 & 0 & 0 & 0 & 0 & 0 & 0 & 0 & 0 & 0 \\
\hline 7 & 0 & $\begin{array}{ll}0 & 0\end{array}$ & 0 & 0 & 0 & 1 & 0 & 0 & 0 & 0 & 0 & 0 & 0 & 0 & 0 & 0 & 0 \\
\hline 8 & $\begin{array}{ll}0 & 0\end{array}$ & $\begin{array}{ll}0 & 0\end{array}$ & 0 & 0 & 0 & 0 & 1 & 0 & 0 & 0 & 0 & 0 & 0 & 0 & 0 & 0 & 0 \\
\hline 9 & $\begin{array}{ll}0 & 0\end{array}$ & $\begin{array}{ll}0 & 0\end{array}$ & 0 & 0 & 0 & 0 & 0 & 1 & 0 & 0 & 0 & 0 & 0 & 0 & 0 & 0 & 0 \\
\hline 10 & 0 & $\begin{array}{ll}0 & 0\end{array}$ & 0 & 0 & 0 & 0 & 0 & 0 & 1 & 0 & 0 & 0 & 0 & 0 & 0 & 0 & 0 \\
\hline 11 & 0 & $\begin{array}{ll}0 & 0\end{array}$ & 0 & 0 & 0 & 0 & 0 & 0 & 0 & 1 & 0 & 0 & 0 & 0 & 0 & 0 & 0 \\
\hline 12 & 0 & $\begin{array}{ll}0 & 0\end{array}$ & 0 & 0 & 0 & 0 & 0 & 0 & 0 & 0 & 1 & 0 & 0 & 0 & 0 & 0 & 0 \\
\hline 13 & $\begin{array}{ll}0 & 0\end{array}$ & $\begin{array}{ll}0 & 0\end{array}$ & 0 & 0 & 0 & 0 & 0 & 0 & 0 & 0 & 0 & 1 & 0 & 0 & 0 & 0 & 0 \\
\hline 14 & $\begin{array}{ll}0 & 0\end{array}$ & $\begin{array}{ll}0 & 0\end{array}$ & 0 & 0 & 0 & 0 & 0 & 0 & 0 & 0 & 0 & 0 & 1 & 0 & 0 & 0 & 0 \\
\hline 15 & $\begin{array}{ll}0 & 0\end{array}$ & $\begin{array}{ll}0 & 0\end{array}$ & 0 & 0 & 0 & 0 & 0 & 0 & 0 & 0 & 0 & 0 & 0 & 0.96 & 0.04 & +0 & 0 \\
\hline 16 & 0 & 0 & 0 & 0 & 0 & 0 & 0 & 0 & 0 & 0 & 0 & 0 & 0 & 0 & 1 & 0 & 0 \\
\hline 17 & 0 & $\begin{array}{ll}0 & 0\end{array}$ & 0 & 0 & 0 & 0 & 0 & 0 & 0 & 0 & 0 & 0 & 0 & 0 & 0 & 1 & 0 \\
\hline 18 & $\begin{array}{ll}0 & 0\end{array}$ & $\begin{array}{ll}0 & 0\end{array}$ & 0 & & 0 & 0 & 0 & 0 & 0 & 0 & 0 & 0 & 0 & 0 & 0 & 0 & 1 \\
\hline
\end{tabular}

Fig. 9: Classification performance - PCC vs SNR -

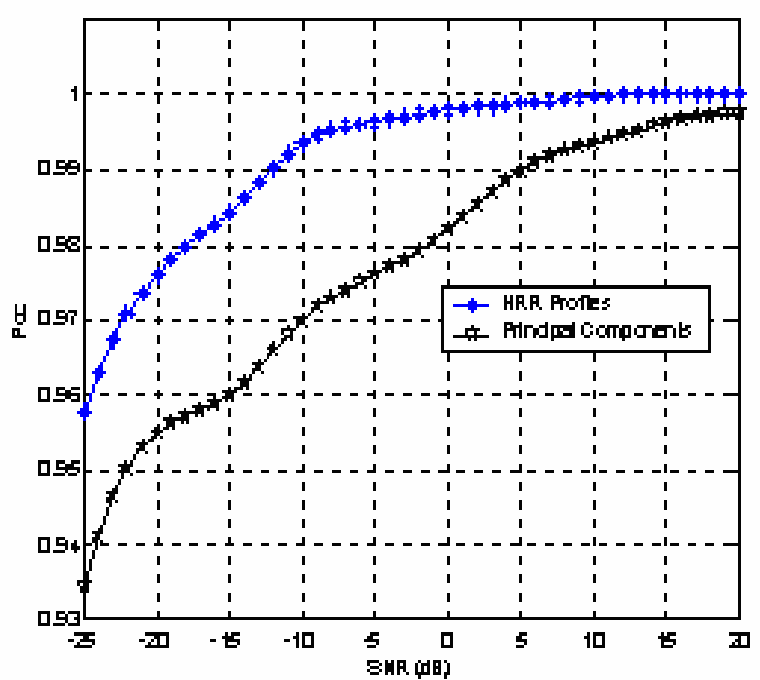

Fig. 8 : Confusion matrix - principal components -

\begin{tabular}{|c|cccccccccccccccccc|}
\hline 1 & $\mathbf{1}$ & 0 & 0 & 0 & 0 & 0 & 0 & 0 & 0 & 0 & 0 & 0 & 0 & 0 & 0 & 0 & 0 & 0 \\
2 & 0 & 0.96 & 0 & 0 & 0 & 0 & 0 & 0 & 0 & 0 & 0 & 0 & 0 & 0 & 0 & 0.04 & 0 & 0 \\
3 & 0 & 0 & $\mathbf{1}$ & 0 & 0 & 0 & 0 & 0 & 0 & 0 & 0 & 0 & 0 & 0 & 0 & 0 & 0 & 0 \\
4 & 0 & 0 & 0 & $\mathbf{1}$ & 0 & 0 & 0 & 0 & 0 & 0 & 0 & 0 & 0 & 0 & 0 & 0 & 0 & 0 \\
5 & 0 & 0 & 0 & 0 & 0.88 & 0 & 0 & 0.08 & 0 & 0 & 0 & 0 & 0 & 0 & 0 & 0 & 0 & 0.04 \\
6 & 0 & 0 & 0 & 0 & 0 & $\mathbf{1}$ & 0 & 0 & 0 & 0 & 0 & 0 & 0 & 0 & 0 & 0 & 0 & 0 \\
7 & 0 & 0 & 0 & 0 & 0 & 0 & $\mathbf{0 . 9 6}$ & 0 & 0 & 0 & 0 & 0 & 0 & 0 & 0 & 0 & 0.04 & 0 \\
8 & 0 & 0 & 0 & 0 & 0 & 0 & 0 & $\mathbf{1}$ & 0 & 0 & 0 & 0 & 0 & 0 & 0 & 0 & 0 & 0 \\
9 & 0 & 0 & 0 & 0 & 0 & 0 & 0 & 0 & $\mathbf{1}$ & 0 & 0 & 0 & 0 & 0 & 0 & 0 & 0 & 0 \\
10 & 0 & 0 & 0 & 0 & 0 & 0 & 0 & 0 & 0 & $\mathbf{0 . 9 6}$ & 0 & 0 & 0 & 0 & 0.04 & 0 & 0 & 0 \\
11 & 0 & 0 & 0 & 0 & 0 & 0 & 0 & 0 & 0 & 0 & $\mathbf{1}$ & 0 & 0 & 0 & 0 & 0 & 0 & 0 \\
12 & 0 & 0 & 0 & 0 & 0 & 0 & 0 & 0 & 0 & 0 & 0 & $\mathbf{1}$ & 0 & 0 & 0 & 0 & 0 & 0 \\
13 & 0 & 0 & 0 & 0 & 0 & 0 & 0 & 0 & 0 & 0 & 0 & 0 & $\mathbf{1}$ & 0 & 0 & 0 & 0 & 0 \\
14 & 0 & 0 & 0 & 0 & 0 & 0 & 0 & 0 & 0 & 0 & 0 & 0 & 0 & $\mathbf{1}$ & 0 & 0 & 0 & 0 \\
15 & 0 & 0 & 0 & 0 & 0 & 0 & 0 & 0 & 0 & 0 & 0 & 0 & 0 & 0 & $\mathbf{0 . 9 6}$ & 0.04 & 0 & 0 \\
16 & 0 & 0 & 0 & 0 & 0 & 0 & 0 & 0 & 0 & 0 & 0 & 0 & 0 & 0 & 0 & $\mathbf{1}$ & 0 & 0 \\
17 & 0 & 0 & 0.08 & 0 & 0 & 0 & 0 & 0 & 0.04 & 0 & 0 & 0 & 0 & 0 & 0 & 0 & $\mathbf{0 . 8 8}$ & 0 \\
18 & 0 & 0 & 0 & 0 & 0 & 0 & 0 & 0 & 0 & 0 & 0 & 0 & 0 & 0 & 0 & 0 & 0 & $\mathbf{1}$
\end{tabular}

Fig. 10 : Classification performance - CCP vs number of the vectors in the training dataset -

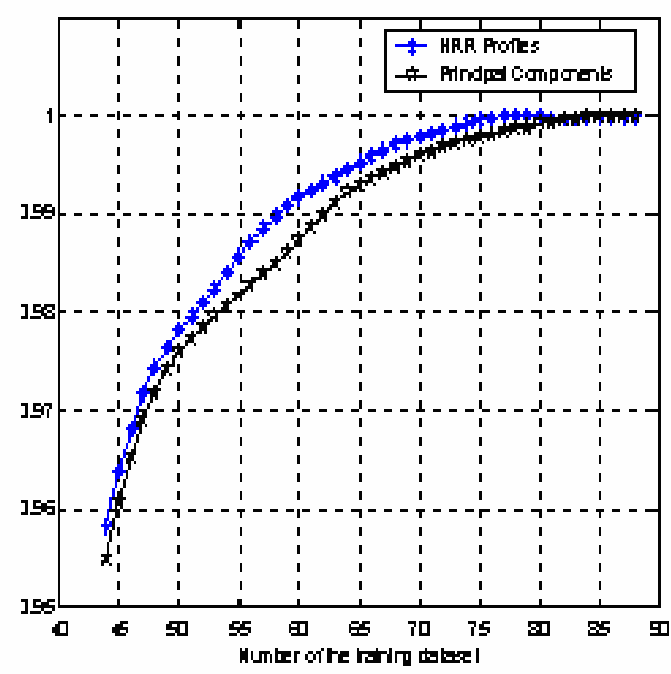

